\title{
Physical comorbidities in men with mood and anxiety disorders: a population-based study
}

\author{
Livia Sanna', Amanda L Stuart ${ }^{2}$, Julie A Pasco ${ }^{2,4}$, Mark A Kotowicz ${ }^{2,4}$, Michael Berk ${ }^{2,3,6,7}$, Paolo Girardi ${ }^{1}$, \\ Sharon L Brennan $2,4,5$ and Lana J Williams ${ }^{2,3^{*}}$
}

\begin{abstract}
Background: The mind-body nexus has been a topic of growing interest. Further data are however required to understand the specific relationship between mood and anxiety disorders and individual physical health conditions, and to verify whether these psychiatric disorders are linked to overall medical burden.

Methods: This study examined data collected from 942 men, 20 to 97 years old, participating in the Geelong Osteoporosis Study. A lifetime history of mood and anxiety disorders was identified using the Structured Clinical Interview for DSM-IV-TR Research Version, Non-patient edition (SCID-I/NP). The presence of medical conditions (lifetime) was self-reported and confirmed by medical records, medication use or clinical data. Anthropometric measurements and socioeconomic status (SES) were determined and information on medication use and lifestyle was obtained via questionnaire. Logistic regression models were used to test the associations.

Results: After adjustment for age, socioeconomic status, and health risk factors (body mass index, physical activity and smoking), mood disorders were associated with gastro oesophageal reflux disease (GORD), recurrent headaches, blackouts and/or epilepsy, liver disorders and pulmonary disease in older people, whilst anxiety disorders were significantly associated with thyroid, GORD and other gastrointestinal disorders, and psoriasis. Increased odds of high medical burden were associated with both mood and anxiety disorders.

Conclusions: Our study provides further population-based evidence supporting the link between mental and physical illness in men. Understanding these associations is not only necessary for individual management, but also to inform the delivery of health promotion messages and health care.
\end{abstract}

Keywords: Mood disorder, Anxiety disorder, Comorbidity, Medical burden, Population-based study, Physical illness

\section{Background}

For centuries, it has been hypothesised and debated that a mind-body interaction exists. Over time, an evidence base has grown to support this notion, yet an incomplete understanding prevails [1,2]. Rates of depression and anxiety are generally higher among the physically ill than in the general population; however, results vary according to the type and severity of the chronic disease and methods of ascertainment [3,4].

Within clinical samples, patients with depression have been found to have a significantly higher number of

\footnotetext{
* Correspondence: lanaw@barwonhealth.org.au

${ }^{2}$ School of Medicine, Deakin University: The Geelong Hospital,

PO Box 281, Geelong 3220, Australia

${ }^{3}$ Department of Psychiatry, The University of Melbourne, Parkville 3010,

Australia

Full list of author information is available at the end of the article
}

somatic symptoms [5] and a higher risk of chronic diseases [6-8], such as coronary heart disease $[9,10]$, congestive heart failure [11], stroke and dementia [12], diabetes $[13,14]$, gastro oesophageal reflux disease (GORD) [15], osteoarthritis and rheumatoid arthritis [16], psoriasis [17], cancer [18], neurological disorders [19], pulmonary disease [20], liver disease [21], thyroid disorders [22] and asthma [23,24], as well as non-specific syndromes such as obesity [25], anaemia [26], renal dysfunction [27], chronic fatigue syndrome [28], chronic headaches [24], and chronic pain [29]. The strength of the association as well as the extent of the evidence varies for each medical condition.

Similarly, anxiety disxorders, have been shown to be related to several medical conditions, such as cardiovascular disease [30], cancer [18], obesity [31] and other

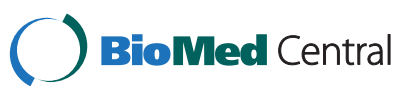

(c) 2013 Sanna et al.; licensee BioMed Central Ltd. This is an Open Access article distributed under the terms of the Creative Commons Attribution License (http://creativecommons.org/licenses/by/2.0), which permits unrestricted use, distribution, and reproduction in any medium, provided the original work is properly cited. 
metabolic disorders [32], irritable bowel syndrome [33], gastrointestinal problems [34], GORD [15], thyroid disorders [35], psoriasis [17] and a higher number of medical symptoms [36]. In addition, as recently reviewed by Culpepper and colleagues, migraine and chronic pain, diabetes, peptic ulcer, arthritis and pulmonary disease are also associated [2].

The co-occurrence of mood or anxiety disorders and physical illness worsens the impact of symptom burden [36], impacts disease course, links to the deteriorating patient's health status and functioning [7,37], affects medication response and treatment adherence [38], and increases the risk of complications [39] and even death [37]. Moreover, the comorbidity between mental and physical illness is relevant in terms of role impairment and work performance [24], as well as quality of life and health service use and costs [40].

The causal pathway between comorbid mental and physical illness is complex and remains unclear. It has been suggested that the bi-directionality of this relationship may involve several mechanisms $[41,42]$ including biological (for example, increased pro-inflammatory cytokines, hypothalamic-pituitary axis deregulation, autonomic nervous system dysfunction, serotonin depletion, metabolic, immune and endocrine changes) [43], psychological (for example, behavioural, psychodynamic and cognitive factors) [44] and social (for example, impaired social support, loneliness, and social disengagement) [45]. Furthermore, psychotropic medication use has been linked to a higher incidence of an array of health outcomes, including diabetes, falls and bleeding, osteoporosis, and sudden cardiac death [46-48].

Enhancing the quality of care for those with mental illness not only can improve mood and anxiety symptoms, but also physical health in patients with comorbid mental and physical illness [49]. Furthermore, treatment for these disorders may influence each other [50]. Thus, estimating the prevalence and understanding the association between mood and anxiety disorders and physical illness is important in order to make more accurate diagnoses and to provide integrated and effective treatment, with regard to syndrome reciprocal influences and medication interactions. Given these data, we aimed to describe the relationship between comorbid mental and physical illness in a large, representative sample of men residing in Australia, utilising structured clinical interviews, medical records, and clinical and self-reported data collected as part of the Geelong Osteoporosis Study (GOS) [51].

\section{Methods}

\section{Participants}

Data were derived from the GOS male cohort, a study originally designed to investigate the epidemiology of osteoporosis in Australia. Originally, an age-stratified, population-based sample of adult men $(\mathrm{n}=1,540$; response 67\%, 20 to 97 years old) was randomly-selected from the Australian Electoral Commission (AEC) rolls for the Barwon Statistical Division between 2001 and 2006. The Barwon Statistical Division is situated in SouthEastern Australia, comprising both rural and urban communities. Further details of the study have been published elsewhere [51].

Of those invited to participate in the five-year followup study $(\mathrm{n}=1,540), 141$ had died, 41 had left the study region, 16 were unable to provide written informed consent, 139 were not able to be contacted and 225 declined to participate resulting in 978 participants ( $81 \%$ of the eligible baseline sample). For this analyses, those who did not undergo psychiatric assessment $(\mathrm{n}=17)$ or provide medical information $(n=19)$ were excluded, resulting in a final sample of 942 eligible men. This study was approved by the Barwon Health Human Research Ethics Committee and written informed consent was obtained from all participants.

\section{Assessments \\ Psychiatric measures}

The Structured Clinical Interview for the Diagnostic and Statistical Manual of Mental Disorders, 4th edition, text revision (DSM-IV-TR) Research Version, Non-patient edition (SCID-I/NP) [52] was used to identify those who had ever experienced a mood disorder, including major depressive disorder, bipolar disorder (types I and II), dysthymia, minor depression, mood disorder due to general medical condition (GMC) and substance-induced mood disorder; and/or an anxiety disorder including panic disorder, agoraphobia, social phobia, specific phobia, obsessive compulsive disorder, generalised anxiety disorder, anxiety disorder due to a medical condition, substanceinduced anxiety disorder or anxiety disorder not otherwise specified. All interviews were conducted by personnel with qualifications in psychology, who were trained using live and videotaped interviews under the supervision of a psychiatrist.

\section{Clinical measures}

Height was measured to the nearest $0.1 \mathrm{~cm}$ using a wallmounted stadiometer and body weight was measured to the nearest $0.1 \mathrm{~kg}$ using electronic scales. Body mass index $\left(\mathrm{BMI} ; \mathrm{kg} / \mathrm{m}^{2}\right)$ was calculated from these measurements.

Lumbar spine and femoral neck bone mineral density (BMD) was measured by dual energy X-ray absorptiometry (DXA) using GE Lunar Prodigy (Prodigy GE Lunar Madison, WI, USA). Long term stability of the machine was tested three times weekly by scanning an anthropomorphic phantom (Hologic). Low bone mass was classified according to the World Health Organisation definition; one or more standard deviations below the 
young normal mean at the femoral neck or spine (L2-L4, posterior-anterior projection) [53].

\section{Medical conditions}

The presence of medical conditions (lifetime) was selfreported and confirmed by medical records, medication use or clinical data, where possible. Musculoskeletal disease was defined by low BMD or self-reported osteoarthritis, ankylosing spondylitis, psoriatic arthritis, rheumatoid arthritis, muscle disease or weakness, low trauma fracture, or self-reported or medicated gout (agents used in gout or hyperuricaemia). Thyroid disorders included self-reported or medicated (thyroid hormones and anti-thyroid agents) hyperthyroidism, hypothyroidism, Graves' disease, Hashimoto's disease, thyroiditis and other unspecified thyroid conditions. Metabolic risk factors included a diagnosis of diabetes, defined by self-report or current medication use (oral hypoglycaemic agents and insulin preparations), obesity defined by a $\mathrm{BMI}>30 \mathrm{~kg} / \mathrm{m}^{2}$ [54], self-reported or medicated hypercholesterolemia (use of cholesterol-lowering agents) and hypertension. Hypertension was characterised by a combination of selfreport and current medication use (antihypertensive, beta-adrenergic blocking agents and diuretics) or a systolic blood pressure of $>140 \mathrm{mmHg}$ or diastolic blood pressure of $>90 \mathrm{mmHg}$. Diagnosis of GORD was based on self-report as were gastrointestinal diseases which include peptic ulcer, chronic gastritis and causes of malabsorption, such as pancreatitis, gastric surgery, chronic diarrhoea, irritable bowel syndrome, inflammatory bowel syndrome and coeliac disease. Cardiovascular disease was defined by a diagnosis of hypertension (as detailed above) or a combination of self-reported or medicated (beta-adrenergic blocking agents, diuretics, anti-arrhythmic, anti-angina, cardiac inotropic agents, adrenergic stimulants, other cardiovascular agents) stroke, transient ischaemic accident (TIA), ischaemic cardiomyopathy, arrhythmia and valve and vascular diseases. Syncope and seizures included self-reported epilepsy, blackouts, fainting and dizzy spells. Self-reported migraine and other recurrent headaches were grouped together. Lifetime pulmonary disease included self-reported asthma, emphysema and chronic bronchitis. Psoriasis was defined by self-report. Liver disease diagnosis, including fatty liver, hepatitis, cirrhosis and liver failure, was also based on self-report. Cancer was defined as any malignant tumour including non-melanoma skin cancer. High medical burden was classified as a diagnosis of three or more conditions listed above.

\section{Other measures}

Smoking status, medication use and physical activity level were obtained by self-report [51]. Reported medication use was cross-referenced with the participants' list of medications or containers and was considered current if the participants reported use at the time of assessment. Men were classified as active if they participated in light to vigorous activity on a regular basis. Alcohol consumption (average grams consumed daily over a 12 month period) was determined by a validated food frequency questionnaire [55]. Tobacco smoking was documented and grouped as current or not. In order to determine socioeconomic status (SES), residential addresses were matched to the corresponding Australian Bureau of Statistics (ABS) Census Collection District (CCD). ABS software was used to determine the Socio-Economic Index for Areas (SEIFA) from the 2006 ABS Census data. SEIFA values summarize the characteristics of subjects within an area, thereby providing a single measure to rank the level of disadvantage at the area level, not of the individual subject. SEIFA values indicate the level of advantage or disadvantage within each CCD, small geographic areas that incorporate approximately 250 houses [56]. These values inform the Index of Relative Socioeconomic Advantage/ Disadvantage (IRSAD), which accounts for various socioeconomic parameters including high and low income, educational attainment ranging from no qualifications to a tertiary degree or higher, the type of occupation from unskilled employment to professional positions, and some measure of wealth (such as owning a car, or number of bedrooms in a dwelling). The relative SES of participants was ascertained by categorizing the sample into quintiles based on cutpoints for the study region [57-59].

\section{Statistical analysis}

Differences in characteristics between those with and without mood and anxiety disorders were compared using chi-square analyses for discrete variables and MannWhitney for non-parametric continuous variables. Logistic regression was used to calculate odds ratios (OR) with 95\% confidence interval (95\% CI) of lifetime medical conditions for those with lifetime mood/anxiety disorders in comparison to those with no mood/anxiety disorder. Models were adjusted for age (model I) and then for age, BMI, SES, physical activity, alcohol consumption and smoking status (model II). Interactions between exposure variables were examined. Each analysis was performed with and without participants with mood disorders due to GMC; no differences in outcome were detected, therefore, those with mood disorder due to GMC were included in all analyses. Values of $P<0.05$ were accepted as significant (including interaction terms). Statistical analyses were performed using Minitab (version 16; Minitab, State College, PA, USA).

\section{Results}

A total of 160 men (17\%) had a lifetime history of mood disorder, of which 139 (86.9\%) were identified with major depressive disorder, 10 (6.3\%) dysthymia, 9 (5.6\%) 
minor depression, 3 (1.9\%) bipolar disorder, 3 (1.9\%) mood disorder due to a GMC and 2 (1.3\%) substance induced mood disorder. Of the 60 participants $(12.2 \%)$ with a history of anxiety disorder, $23(38.3 \%)$ met criteria for panic disorder, 15 (25\%) post-traumatic stress disorder, 7 (11.7\%) specific phobia, 6 (10\%) social phobia, 5 (8.3\%) generalized anxiety disorder, 5 (8.3\%) obsessive compulsive disorder and $3(5 \%)$ anxiety disorder not otherwise specified. Participants with a history of mood or anxiety disorder were younger than those without; otherwise the groups were similar (Table 1).

\section{Mood disorder}

After adjustments for age, mood disorder was associated with increased odds of GORD (OR 2.41, 95\% CI 1.48 to 3.00, $P=0.027$ ), recurrent headaches (OR 2.46, 95\% CI 1.29 to $4.69, \mathrm{P}=0.007$ ), syncope and seizures (OR 2.41,
95\% CI 1.31 to $3.09, P=0.002)$ and liver disorders (OR $2.41,95 \% \mathrm{CI} 1.40$ to $4.98, P=0.003)$. Furthermore, a history of mood disorder was associated with increased odds of high medical burden (age-adjusted OR 1.80, 95\% CI 1.16 to 2.77, $P=0.008$ ). Mood disorders tended to be associated with musculoskeletal disease (OR 1.43, 95\% CI 0.93 to 2.21, $P=0.104$ ) and gastrointestinal disorders (OR 1.47, 95\% CI 0.93 to 2.30, $P=0.096$ ). Age was an effect modifier in the association between mood disorders and pulmonary disease. Among older men ( $\geq 60$ years), a lifetime history of mood disorder was associated with increased odds of pulmonary disease (age-adjusted OR $2.75,95 \%$ CI 1.45 to $5.21, P=0.002$ ); no association was detected for those younger than 60 years $(P>0.05)$. These relationships remained significant after further adjustment for BMI, SES, physical activity, alcohol consumption and smoking status (Table 2). No association was observed

Table 1 Characteristics for the total group and men with or without lifetime history of mood disorder and anxiety disorder

\begin{tabular}{|c|c|c|c|c|c|c|c|c|}
\hline & & \multirow{3}{*}{$\begin{array}{c}\text { Total } \\
\text { Number }=942\end{array}$} & \multicolumn{3}{|c|}{ Mood disorder } & \multicolumn{3}{|c|}{ Anxiety disorder } \\
\hline & & & Yes & No & $P$ & Yes & No & $P$ \\
\hline & & & Number $=160$ & Number $=782$ & & Number $=60$ & Number $=\mathbf{8 8 2}$ & \\
\hline \multicolumn{2}{|l|}{ Age at interview (years) } & $59.3(45.7,73.2)$ & $52.8(42.6,64.4)$ & $60.9(46.9,75.4)$ & $<0.001$ & $56.2(41.1,64.3)$ & $59.9(46.0,74.0)$ & 0.013 \\
\hline \multicolumn{2}{|c|}{ Body mass index $\left(\mathrm{kg} / \mathrm{m}^{2}\right)$} & $27.1(24.7,29.6)$ & $27.1(24.6,29.6)$ & $27.1(24.8,29.8)$ & 0.671 & $27.7(25.1,30.3)$ & $27.1(24.6,29.6)$ & 0.257 \\
\hline \multirow[t]{5}{*}{$\begin{array}{l}\text { Socioeconomic status } \\
\text { (IRSAD) }\end{array}$} & $\begin{array}{l}\text { Quintile } 1 \text { (most } \\
\text { disadvantaged) }\end{array}$ & $153(16.2 \%)$ & $24(15.0 \%)$ & $129(16.5 \%)$ & 0.581 & $6(10.0 \%)$ & $147(16.7 \%)$ & 0.147 \\
\hline & Quintile 2 & $189(20.1 \%)$ & $27(16.9 \%)$ & $162(20.7 \%)$ & & $12(20.0 \%)$ & $177(20.1 \%)$ & \\
\hline & Quintile 3 & $182(19.3 \%)$ & $29(18.1 \%)$ & $153(19.6 \%)$ & & $8(13.3 \%)$ & $174(19.7 \%)$ & \\
\hline & Quintile 4 & $202(21.4 \%)$ & $37(23.1 \%)$ & $165(21.1 \%)$ & & $13(21.7 \%)$ & $189(21.4 \%)$ & \\
\hline & Quintile 5 & $216(22.9 \%)$ & $43(26.9 \%)$ & $173(22.1 \%)$ & & $21(35.0 \%)$ & $195(22.1 \%)$ & \\
\hline \multicolumn{2}{|l|}{ Physically active } & $674(71.9 \%)$ & $108(67.5 \%)$ & $566(72.8 \%)$ & 0.179 & $46(76.7 \%)$ & $628(71.5 \%)$ & 0.392 \\
\hline \multicolumn{2}{|l|}{ Smokers (current) } & $105(11.2 \%)$ & $23(14.5 \%)$ & $82(10.5 \%)$ & 0.153 & $10(16.7 \%)$ & $95(10.8 \%)$ & 0.166 \\
\hline \multicolumn{2}{|c|}{ Alcohol consumption (g/day) } & $12.4(2.2,28.8)$ & $17.3(2.0,34.3)$ & $11.9(2.2,28.3)$ & 0.156 & $20.3(2.8,28.7)$ & $12.0(2.8,28.7)$ & 0.179 \\
\hline \multicolumn{2}{|l|}{ Musculoskeletal disease } & $706(77.0 \%)$ & $123(79.4 \%)$ & $583(76.5 \%)$ & 0.443 & $47(79.7 \%)$ & $659(76.8 \%)$ & 0.614 \\
\hline \multicolumn{2}{|l|}{ Thyroid disorders } & $21(2.2 \%)$ & $4(2.5 \%)$ & $17(2.2 \%)$ & 0.799 & $4(6.7 \%)$ & $17(1.9 \%)$ & 0.016 \\
\hline \multicolumn{2}{|l|}{ Metabolic risk factors } & $665(74.3 \%)$ & $107(72.8 \%)$ & $558(74.6 \%)$ & 0.646 & $46(79.3 \%)$ & $619(74.0 \%)$ & 0.367 \\
\hline \multicolumn{2}{|l|}{ GORD } & $124(13.2 \%)$ & $29(18.1 \%)$ & $95(12.1 \%)$ & 0.042 & $16(26.7 \%)$ & $108(12.2 \%)$ & 0.001 \\
\hline \multicolumn{2}{|c|}{ Gastrointestinal disorders } & $164(17.4 \%)$ & $31(19.4 \%)$ & $133(17.0 \%)$ & 0.472 & $16(26.7 \%)$ & $148(16.8 \%)$ & 0.051 \\
\hline \multicolumn{2}{|l|}{ Recurrent headaches } & $50(5.3 \%)$ & $15(9.4 \%)$ & $35(4.5 \%)$ & 0.012 & $2(3.3 \%)$ & $48(5.4 \%)$ & 0.481 \\
\hline \multicolumn{2}{|l|}{ Syncope and seizures } & $157(16.7 \%)$ & $37(23.1 \%)$ & $120(15.4 \%)$ & 0.016 & $12(20.0 \%)$ & $145(16.4 \%)$ & 0.474 \\
\hline \multicolumn{2}{|l|}{ Cardiovascular disease } & $598(68.5 \%)$ & $91(65.5 \%)$ & $507(69.1 \%)$ & 0.401 & $34(63.0 \%)$ & $564(68.9 \%)$ & 0.366 \\
\hline \multirow[t]{3}{*}{ Pulmonary disease } & All & $178(18.9 \%)$ & - & - & & $11(18.3 \%)$ & $167(18.9 \%)$ & 0.908 \\
\hline & $<60$ years old & 90/478 (18.8\%) & $19 / 109(17.4 \%)$ & $71 / 369(19.2 \%)$ & 0.671 & - & - & - \\
\hline & $\geq 60$ years old & $88 / 464(19.0 \%)$ & 18/51 (35.3\%) & $70 / 416$ (17\%) & 0.002 & - & - & - \\
\hline \multicolumn{2}{|l|}{ Liver disorders } & $55(5.8 \%)$ & $16(10 \%)$ & $39(5 \%)$ & 0.014 & $3(5.0 \%)$ & $52(5.9 \%)$ & 0.775 \\
\hline \multicolumn{2}{|l|}{ Cancer } & $162(17.2 \%)$ & $20(12.5 \%)$ & $142(18.2 \%)$ & 0.084 & $8(13.3 \%)$ & $154(17.5 \%)$ & 0.412 \\
\hline \multicolumn{2}{|l|}{ Psoriasis } & $41(4.3 \%)$ & $9(5.6 \%)$ & $32(4.1 \%)$ & 0.387 & $5(8.3 \%)$ & $36(4.1 \%)$ & 0.118 \\
\hline \multicolumn{2}{|l|}{ High medical burden } & $548(62.2 \%)$ & $90(62.9 \%)$ & $458(62.1 \%)$ & 0.843 & $40(70.2 \%)$ & $508(61.7 \%)$ & 0.199 \\
\hline
\end{tabular}

Values are given as median (interquartile range) or number (\%). Missing data: BMI, number = 28; physically active, number = 4; smokers, number = 5; musculoskeletal disease, number $=25$; metabolic risk factors, number $=47$; cardiovascular disease, number $=69$; high medical burden, number $=61$. GORD, gastro oesophageal reflux disease; IRSAD, Index of Relative Socioeconomic Advantage/Disadvantage. 
between mood disorders and thyroid disorders, metabolic risk factors, cardiovascular disease, cancer and psoriasis.

\section{Anxiety disorder}

After adjustment for age, anxiety disorder was associated with increased likelihood of thyroid disease (OR 5.29, 95\% CI 1.63 to $7.14, P=0.005$ ), GORD (OR 3.84, 95\% CI 2.01 to $7.33, P<0.001$ ), gastrointestinal disease (OR 2.22, $95 \%$ CI 1.20 to $4.10, P=0.011)$ and high medical burden (OR 2.82, 95\% CI 1.43 to $5.53, P=0.003$ ). Anxiety disorder also tended to be associated with metabolic risk factors (OR 1.92, 95\% CI 0.96 to 3.83, $P=0.066$ ). Further adjustment for BMI, SES, physical activity, alcohol consumption and smoking status did not affect these outcomes (Table 2). The relationship between lifetime anxiety disorder and metabolic risk factors and lifetime anxiety disorders and psoriasis reached significance following adjustment for age, BMI, SES, physical activity, alcohol consumption and smoking status (OR 2.20, 95\% CI 1.07 to $4.53, P=0.032$ and OR $2.77,95 \%$ CI 1.00 to $7.67, P$ $=0.049$, respectively). There were no associations detected between anxiety disorders and musculoskeletal disease, recurrent headaches, syncope and seizures, cardiovascular disease, pulmonary disease, liver disorders or cancer.

\section{Discussion}

Our population-based study reports associations between mood and anxiety disorders and physical illness. Mood

Table 2 Age-adjusted (model I) and fully-adjusted (model II) odds ratios for medical comorbidities in men with lifetime history of mood and anxiety disorders

\begin{tabular}{|c|c|c|c|c|c|c|c|c|}
\hline & & \multirow[b]{2}{*}{ Model } & \multicolumn{3}{|c|}{ Mood disorders } & \multicolumn{3}{|c|}{ Anxiety disorders } \\
\hline & & & Odds ratio & $95 \% \mathrm{Cl}$ & $P$ value & Odds ratio & $95 \% \mathrm{Cl}$ & $P$ value \\
\hline \multirow{2}{*}{\multicolumn{2}{|c|}{ Musculoskeletal disease }} & 1 & 1.43 & (0.93 to 2.21$)$ & 0.104 & 1.39 & (0.72 to 2.71$)$ & 0.328 \\
\hline & & $\|$ & 1.47 & (0.94 to 2.31$)$ & 0.092 & 1.70 & (0.85 to 3.43$)$ & 0.135 \\
\hline \multirow{2}{*}{\multicolumn{2}{|c|}{ Thyroid disorders }} & I & 1.64 & (0.52 to 5.12$)$ & 0.396 & 5.29 & (1.63 to 7.14$)$ & 0.005 \\
\hline & & $\|$ & 1.81 & (0.56 to 5.83$)$ & 0.321 & 5.54 & (1.64 to 18.64$)$ & 0.006 \\
\hline \multirow{2}{*}{\multicolumn{2}{|c|}{ Metabolic risk factors }} & 1 & 1.30 & (0.85 to 1.99$)$ & 0.234 & 1.92 & (0.96 to 3.83 ) & 0.066 \\
\hline & & $\|^{\mathrm{a}}$ & 1.29 & (0.83 to 2.00$)$ & 0.265 & 2.20 & (1.07 to 4.53$)$ & 0.032 \\
\hline \multirow{2}{*}{\multicolumn{2}{|c|}{ GORD }} & 1 & 2.41 & (1.48 to 3.00$)$ & $<0.001$ & 3.84 & (2.01 to 7.33 ) & $<0.001$ \\
\hline & & $\|$ & 2.67 & (1.60 to 4.47$)$ & $<0.001$ & 4.25 & (2.18 to 8.26$)$ & $<0.001$ \\
\hline \multirow{2}{*}{\multicolumn{2}{|c|}{ Gastrointestinal disorders }} & 1 & 1.47 & (0.93 to 2.30$)$ & 0.096 & 2.22 & (1.20 to 4.10$)$ & 0.011 \\
\hline & & $\|$ & 1.46 & (0.91 to 2.34$)$ & 0.112 & 2.40 & (1.28 to 4.50$)$ & 0.006 \\
\hline \multirow{2}{*}{\multicolumn{2}{|c|}{ Recurrent headaches }} & 1 & 2.46 & (1.29 to 4.69$)$ & 0.007 & 0.63 & (0.15 to 2.69$)$ & 0.537 \\
\hline & & $\|$ & 2.53 & (1.30 to 4.96$)$ & 0.007 & 0.67 & (0.16 to 2.89$)$ & 0.592 \\
\hline \multirow{2}{*}{\multicolumn{2}{|c|}{ Syncope and seizures }} & 1 & 2.01 & (1.31 to 3.09 ) & 0.002 & 1.46 & (0.75 to 2.85$)$ & 0.263 \\
\hline & & $\|$ & 2.01 & (1.28 to 3.16$)$ & 0.002 & 1.55 & (0.78 to 3.07 ) & 0.207 \\
\hline \multirow{2}{*}{\multicolumn{2}{|c|}{ Cardiovascular disease }} & 1 & 1.27 & (0.82 to 1.93$)$ & 0.292 & 1.93 & (0.60 to 2.13$)$ & 0.708 \\
\hline & & $\|$ & 1.28 & (0.82 to 2.01$)$ & 0.276 & 1.15 & (0.59 to 2.25$)$ & 0.678 \\
\hline \multirow[t]{6}{*}{ Pulmonary disease } & All & 1 & - & - & - & 0.95 & (0.48 to 1.86$)$ & 0.874 \\
\hline & & $\|$ & - & - & - & 1.02 & (0.51 to 2.03 ) & 0.956 \\
\hline & $<60$ years old & 1 & 0.90 & (0.52 to 1.58$)$ & 0.725 & - & - & - \\
\hline & & $\|$ & 1.01 & (0.57 to 1.79$)$ & 0.971 & - & - & - \\
\hline & $\geq 60$ years old & 1 & 2.75 & (1.45 to 5.21$)$ & 0.002 & - & - & - \\
\hline & & $\|$ & 2.65 & (1.34 to 5.21$)$ & 0.005 & - & - & - \\
\hline \multirow{2}{*}{\multicolumn{2}{|c|}{ Liver disorders }} & 1 & 2.64 & (1.40 to 4.98$)$ & 0.003 & 0.97 & (0.29 to 3.24$)$ & 0.964 \\
\hline & & $\|$ & 3.03 & (1.57 to 5.83$)$ & 0.001 & 1.03 & (0.30 to 3.46$)$ & 0.967 \\
\hline \multirow{2}{*}{\multicolumn{2}{|c|}{ Cancer }} & 1 & 0.95 & (0.56 to 1.61$)$ & 0.839 & 1.03 & (0.47 to 2.29 ) & 0.933 \\
\hline & & $\|$ & 0.90 & (0.52 to 1.56$)$ & 0.706 & 1.03 & (0.46 to 2.32$)$ & 0.938 \\
\hline \multirow{2}{*}{\multicolumn{2}{|c|}{ Psoriasis }} & 1 & 1.63 & (0.75 to 3.55$)$ & 0.219 & 2.44 & (0.91 to 6.57$)$ & 0.076 \\
\hline & & $\|$ & 1.41 & (0.51 to 2.91$)$ & 0.648 & 2.77 & (1.00 to 7.67$)$ & 0.049 \\
\hline \multirow{2}{*}{\multicolumn{2}{|c|}{ High medical burden }} & 1 & 1.80 & (1.16 to 2.77$)$ & 0.008 & 2.82 & (1.43 to 5.53$)$ & 0.003 \\
\hline & & $\|^{\mathrm{a}}$ & 1.86 & (1.19 to 2.91$)$ & 0.007 & 3.23 & (1.61 to6.47) & 0.001 \\
\hline
\end{tabular}


disorders were associated with increased risk of many of the disease groups (GORD, neurological features, such as recurrent headaches and syncope and seizures, liver disorders and pulmonary diseases in older men). Anxiety disorders presented a different profile; thyroid disorders, GORD, gastrointestinal disease, metabolic risk factors, and psoriasis were more common among individuals with anxiety disorder. Importantly, mood and anxiety disorders were both associated with high medical burden.

Our results confirm other population-based data investigating the association between mood disorder and GORD [60,61]. In a sample of over 60,000 participants residing in Norway, those identified with depressive, anxiety and comorbid symptoms, as measured by the Hospital Anxiety and Depression Scale, had a two- to three-fold increased risk of reflux symptoms, self-reported severe symptoms of recurrent heartburn or acid regurgitation [62]. Moreover, mood disorders have also been shown consistently to be more prevalent in patients with GORD in clinical practice [15,63].

Chronic headaches are high prevalence disorders, with as many as $46 \%$ of the adult population reporting headaches, $11 \%$ migraines and $42 \%$ tension headaches [64]. Similar to our findings and other population-based studies [65,66], Scott et al. [24] utilising data pooled from 18 general population surveys reported those identified with either non-comorbid depression or comorbid depression and anxiety, as measured by the Composite International Diagnostic Interview, had an age and gender adjusted odds ratio of 2.5 and 4.0, respectively, for chronic headaches.

In regard to syncope and seizures, our results support Morgan et al. [67] who reported fainting, blackouts and dizziness, for which there is no adequate physical explanation, were associated with undiagnosed psychiatric disorders. Depression has also been shown to co-occur with epilepsy. Recently, the association has been viewed according to the diathesis-stress model, with depression resulting from the chronic stress associated with the threat of recurring seizures, as there is little evidence linking specific epilepsy related factors (for example, focus site) to low mood [68].

Akin to our results, Wilhelm and colleagues [69] reported an association between depression and liver pathology in a population-based survey of 10,641 adults; however, the relationship was not sustained following adjustment for demographic and behavioural confounders including drinking behaviour. Excessive alcohol consumption is known to be highly correlated with liver disease [21]; however, the association persisted following correction for alcohol in our study.

In our sample, only older men with a mood disorder were at increased risk of pulmonary disease. Although the association between asthma and mood disorder is evident across the full adult age range [23], chronic bronchitis and emphysema are more common among older people and most likely contribute to the different pattern observed for older and younger men. Furthermore, pulmonary disease can be considered in stages reflecting severity, a factor we could not explore [70].

Musculoskeletal and gastrointestinal disorders tended to be associated with mood disorders, although we speculate that the heterogeneous groupings we employed may have diluted associations in our sample population. Mood disorders and symptomology have previously been shown to be associated with low BMD and subsequent fracture, where both biological and medication related processes are thought to play a role [71]. Similarly, mood disorders have been shown to be associated with gastrointestinal disorders in both clinical and population-based samples [72-74].

In contrast to other population-based studies, we did not detect a relationship between mood disorders and thyroid disorders, metabolic risk factors, cardiovascular disease, cancer and psoriasis in this sample of men. The link between mood disorders and cardiovascular disease, thyroid disorders and metabolic risk factors, in particular, is well documented $[22,24,30]$. We hypothesize that these results may be influenced by a healthy participant bias, a common issue where study participants are required to be healthy enough to attend the research centre. Furthermore, disease grouping and data collection limited our ability to identify the degree of illness severity (that is, severe stroke, TIA and medically controlled hypertension were grouped) or time since onset of the physical condition.

As with mood disorders, GORD and gastrointestinal disorders were also associated with anxiety disorders. Anxiety has been previously considered to be a nondisease related factor that impacts negatively on quality of life associated with GORD [75] and, as previously discussed, is commonly observed within population-based samples reporting GORD symptoms [62]. Furthermore, data from the present study concur with previous studies indicating that those with anxiety disorder have higher rates of gastrointestinal disorders [34].

Psoriasis has been previously associated with anxiety disorders. Harter and colleagues [34] demonstrated that patients with a lifetime history of generalised anxiety disorder or panic disorder reported significantly higher lifetime prevalence rates for dermatological disorders, including psoriasis. Why this association is seen with anxiety disorders only in our sample population is unclear.

Thyroid disorders and metabolic risk factors have also been associated with anxiety disorders. In our study, anxiety was linked to a combination of the most common risk factors for metabolic disorders, such as hypertension, diabetes, hypercholesterolemia and obesity, 
which Culpepper and colleagues reported to be all likely due to a prolonged stress response in patients with untreated anxiety disorder [2]. Similarly, Simon et al. [35] reported an increased risk of thyroid disorders in patients with generalised anxiety disorder, social phobia or panic disorder and recommended screening for thyroid dysfunction in patients with anxiety disorders.

Our data suggest that both mood and anxiety disorders are associated with overall medical burden. These findings are consistent with previous studies showing both depression and anxiety to be associated with an increased number of somatic conditions [5,76]. It is plausible that this relationship may be due to mood and anxiety disorders causing physiological changes, as well as poorer self-care and treatment adherence, which in turn increase medical burden [36]. On the other hand, an increased physical burden, causing functional impairment, may result in the development of an anxiety and/ or mood disorder, which have been shown to have a negative impact on clinical outcomes [77].

A major strength of our study is that the sample population spans the full adult age range, in contrast to previous studies that have mainly focused on older patients. An age interaction was only evident when exploring the association between mood disorders and pulmonary disease; thus the relationship between mental illness and each of the physical conditions was consistent across all ages. Further strengths of the study include the measurement of mood and anxiety disorders, diagnoses were made utilising semi-structured clinical interviews (SCID-IV), a gold standard tool, and the consideration of several possible confounding factors. However, our observations must be considered with caution. Ascertaining medical conditions by a self-report checklist may be compromised by imperfect recall and response bias error. Although many of these disorders were based on self-report of a physician's diagnosis, which have been demonstrated to generally agree with medical record data [78], where possible this was confirmed by medical records, medication use or clinical data. The cross-sectional nature of the study does not allow verification of a cause-effect relationship between mental and physical illness, longitudinal studies are needed to determine the directionality of this relationship. Finally, we were unable to make a distinction between diseases with an episodic course and those with ongoing symptoms, which may impact differently on psychological status.

\section{Conclusion}

Our study provides further population-based evidence supporting the link between mental and physical illness in men. Recognising the link between these illnesses is important in order to manage the development of mood and anxiety disorders in response to a medical condition, or the presence of physical pathologies due to predisposing psychiatric disorders. Integrating treatment approaches and monitoring comorbidity of mental and physical illnesses is likely to improve disease course and outcome as well as enhance patients' functional and health status, potentially reducing healthcare utilisation.

\section{Abbreviations}

ABS: Australian Bureau of Statistics; BMD: Bone mineral density; BMI: Body mass index; Cl: Confidence interval; DSM-IV-TR: Diagnostic and Statistical Manual for Mental Disorders, 4th edition, text revision; DXA: Dual energy X-ray absorptiometry; GMC: General medical condition; GORD: Gastro oesophageal reflux disease; GOS: Geelong Osteoporosis Study; IRSAD: Index of Relative Socioeconomic Advantage/Disadvantage; SCID-I/NP: Structured clinical interview for DSM-IV-TR research version, non-patient edition; SEIFA: Socioeconomic Index for Areas; SES: Socioeconomic status;

TIA: Transient ischaemic accident.

\section{Competing interests}

Livia Sanna, Amanda L Stuart, Mark A Kotowicz, and Sharon L Brennan have no conflicts of interest, including specific financial interests and relationships and affiliations relevant to the subject matter or materials discussed in the manuscript. Paolo Girardi has in the past three years received research support from Lilly and Janssen, participated in advisory boards for Lilly, Organon, Pfizer, and Schering, and received honoraria from Lilly and Organon. Julie A Pasco has received speaker fees from Amgen, Eli Lilly and Sanofi-Aventis and funding from the Geelong Region Medical Research Foundation, Barwon Health, Perpetual Trustees, the Dairy Research and Development Corporation, The University of Melbourne, the Ronald Geoffrey Arnott Foundation, ANZ Charitable Trust, the American Society for Bone and Mineral Research, Amgen (Europe) GmBH and the NHMRC. Michael Berk has received Grant/Research Support from the NIH, Simons Foundation, CRC for Mental Health, Stanley Medical Research Institute, MBF, NHMRC, Beyond Blue, Geelong Medical Research Foundation, Bristol Myers Squibb, Eli Lilly, Glaxo SmithKline, Organon, Novartis, Mayne Pharma, Servier and Astra Zeneca. He has been a paid consultant for Astra Zeneca, Bristol Myers Squibb, Eli Lilly, Glaxo SmithKline, Janssen Cilag, Lundbeck and Pfizer and a paid speaker for Astra Zeneca, Bristol Myers Squibb, Eli Lilly, Glaxo SmithKline, Janssen Cilag, Lundbeck, Organon, Pfizer, Sanofi Synthelabo, Solvay and Wyeth. Lana J Williams has received Grant/Research support from Eli Lilly, Pfizer, The University of Melbourne, Deakin University and the NHMRC.

\section{Authors' contributions}

LS and ALS took part in the conception and design of the study, acquisition of the data, data cleaning and statistical analysis, interpretation of the analysis and took primary responsibility for writing the manuscript. JAP and MAK took part in the conception and design of the study, interpretation of the analysis and critically revised the manuscript. MB, PG and SLB took part in the interpretation of data and critically revised the manuscript. LJW took part in the conception and design of the study, interpretation of the analysis, critically revised and supervised the writing of the manuscript. All authors read and approved the final manuscript.

\section{Acknowledgments}

The study was funded by the National Health and Medical Research Council (NHMRC) of Australia. Sharon L Brennan is supported by a NHMRC Early Career Fellowship (1012472). The funding providers played no role in the design or conduct of the study; collection, management, analysis, and interpretation of the data; or in preparation, review, or approval of the manuscript. The authors acknowledge the men who participated in the study.

\section{Author details}

${ }^{1}$ Unit of Psychiatry, Neurosciences, Mental Health and Sensory Organs Department (NeSMOS), Faculty of Medicine and Psychology, Sant'Andrea Hospital, Sapienza University of Rome, Via di Grottarossa 1035-1037 00189 Rome, Italy. 'School of Medicine, Deakin University: The Geelong Hospital, PO Box 281, Geelong 3220, Australia. ${ }^{3}$ Department of Psychiatry, The University of Melbourne, Parkville 3010, Australia. ${ }^{4}$ NorthWest Academic Centre, Department of Medicine, The University of Melbourne, Western Health, 176 Furlong Road, St Albans 3021, Australia. ${ }^{5}$ Australian Institute of 
Musculo-Skeletal Science, NorthWest Academic Centre, The University of Melbourne, 176 Furlong Road, St Albans 3021, Australia. ${ }^{6}$ Orygen Youth Health, 35 Poplar Road, Parkville 3052, Australia. ${ }^{7}$ Florey Institute for Neuroscience and Mental Health, The University of Melbourne, Parkville 3010, Australia.

Received: 13 July 2012 Accepted: 4 April 2013

Published: 24 April 2013

\section{References}

1. Evans DL, Charney DS, Lewis L, Golden RN, Gorman JM, Krishnan KR, Nemeroff CB, Bremner JD, Carney RM, Coyne JC, Delong MR, Frasure-Smith N, Glassman AH, Gold PW, Grant I, Gwyther L, Ironson G, Johnson RL, Kanner AM, Katon WJ, Kaufmann PG, Keefe FJ, Ketter T, Laughren TP, Leserman J, Lyketsos CG, McDonald WM, McEwen BS, Miller AH, Musselman D, et al: Mood disorders in the medically ill: scientific review and recommendations. Biol Psychiatry 2005, 58:175-189.

2. Culpepper L: Generalized anxiety disorder and medical illness. J Clin Psychiatry 2009, 70:20-24.

3. Liew HP: Depression and chronic illness: a test of competing hypotheses. J Health Psychol 2012, 17:100-109.

4. Clarke DM, Currie KC: Depression, anxiety and their relationship with chronic diseases: a review of the epidemiology, risk and treatment evidence. Med J Aust 2009, 190:S54-S60.

5. Katon W, Lin E, Von Korff M, Russo J, Lipscomb P, Bush T: Somatization: a spectrum of severity. Am J Psychiatry 1991, 148:34-40.

6. Katon W, Ciechanowski P: Impact of major depression on chronic medical illness. J Psychosom Res 2002, 53:859-863.

7. Taylor D, Meader N, Bird V, Pilling S, Creed F, Goldberg D: Pharmacological interventions for people with depression and chronic physical health problems: systematic review and meta-analyses of safety and efficacy. Br J Psychiatry 2011, 198:179-188.

8. Gunn JM, Ayton DR, Densley K, Pallant JF, Chondros P, Herrman HE, Dowrick CF: The association between chronic illness, multimorbidity and depressive symptoms in an Australian primary care cohort. Soc Psychiatry Psychiatr Epidemiol 2012, 47:175-184.

9. Van der Kooy K, van Hout H, Marwijk H, Marten H, Stehouwer C, Beekman A: Depression and the risk for cardiovascular diseases: systematic review and meta analysis. Int J Geriatr Psychiatry 2007, 22:613-626.

10. Goldston K, Baillie AJ: Depression and coronary heart disease: a review of the epidemiological evidence, explanatory mechanisms and management approaches. Clin Psychol Rev 2008, 28:288-306.

11. Gottlieb SS, Khatta M, Friedmann E, Einbinder L, Katzen S, Baker B, Marshall J, Minshall S, Robinson S, Fisher ML, Potenza M, Sigler B, Baldwin C, Thomas SA: The influence of age, gender, and race on the prevalence of depression in heart failure patients. J Am Coll Cardiol 2004, 43:1542-1549.

12. Bogner HR, Cary MS, Bruce ML, Reynolds CF 3rd, Mulsant B, Ten Have T, Alexopoulos GS: The role of medical comorbidity in outcome of major depression in primary care: the PROSPECT study. Am J Geriatr Psychiatry 2005, 13:861-868.

13. Mezuk B, Eaton WW, Albrecht S, Golden SH: Depression and type 2 diabetes over the lifespan: a meta-analysis. Diabetes Care 2008 31:2383-2390

14. Lin EH, Korff MV, Alonso J, Angermeyer MC, Anthony J, Bromet E, Bruffaerts R, Gasquet I, de Girolamo G, Gureje O, Haro JM, Karam E, Lara C, Lee S, Levinson D, Ormel JH, Posada-Villa J, Scott K, Watanabe M, Williams D: Mental disorders among persons with diabetes-results from the World Mental Health Surveys. J Psychosom Res 2008, 65:571-580

15. Pacini F, Calabrese C, Cipolletta L, Valva MD, Russo A, Savarino V, Vigneri S: Burden of illness in Italian patients with gastro-oesophageal reflux disease. Curr Med Res Opin 2005, 21:495-502.

16. Covic T, Tyson G, Spencer D, Howe G: Depression in rheumatoid arthritis patients: demographic, clinical, and psychological predictors. J Psychosom Res 2006, 60:469-476.

17. Hayes J, Koo J: Psoriasis: depression, anxiety, smoking, and drinking habits. Dermatol Ther 2010, 23:174-180.

18. Mitchell AJ, Chan M, Bhatti H, Halton M, Grassi L, Johansen C, Meader N: Prevalence of depression, anxiety, and adjustment disorder in oncological, haematological, and palliative-care settings: a meta-analysis of 94 interview-based studies. Lancet Oncol 2011, 12:160-174.
19. Lyness JM, Niculescu A, Tu X, Reynolds CF 3rd, Caine ED: The relationship of medical comorbidity and depression in older, primary care patients. Psychosomatics 2006, 47:435-439.

20. Zhang MW, Ho RC, Cheung MW, Fu E, Mak A: Prevalence of depressive symptoms in patients with chronic obstructive pulmonary disease: a systematic review, meta-analysis and meta-regression. Gen Hosp Psychiatry 2011, 33:217-223.

21. Weinstein AA, Kallman Price J, Stepanova M, Poms LW, Fang Y, Moon J, Nader F, Younossi ZM: Depression in patients with nonalcoholic fatty liver disease and chronic viral hepatitis B and C. Psychosomatics 2011 52:127-132.

22. Hage MP, Azar ST: The link between thyroid function and depression. J Thyroid Res 2012, 2012:590648.

23. Patten SB, Williams JV, Lavorato DH, Modgill G, Jette N, Eliasziw M: Major depression as a risk factor for chronic disease incidence: longitudinal analyses in a general population cohort. Gen Hosp Psychiatry 2008, 30:407-413.

24. Scott KM, Bruffaerts R, Tsang A, Ormel J, Alonso J, Angermeyer MC, Benjet C, Bromet E, de Girolamo G, de Graaf R, Gasquet I, Gureje O, Haro JM, He Y, Kessler RC, Levinson D, Mneimneh ZN, Oakley Browne MA, Posada-Villa J, Stein DJ, Takeshima T, Von Korff M: Depression-anxiety relationships with chronic physical conditions: results from the World Mental Health Surveys. J Affect Disord 2007, 103:113-120.

25. Scott KM, McGee MA, Wells JE, Oakley Browne MA: Obesity and mental disorders in the adult general population. J Psychosom Res 2008, 64:97-105.

26. Onder G, Penninx BW, Cesari M, Bandinelli S, Lauretani F, Bartali B, Gori AM, Pahor M, Ferrucci L: Anemia is associated with depression in older adults: results from the InCHIANTI study. J Gerontol A Biol Sci Med Sci 2005 , 60:1168-1172

27. Guzman SJ, Nicassio PM: The contribution of negative and positive illness schemas to depression in patients with end-stage renal disease. J Behav Med 2003, 26:517-534.

28. Barsky AJ, Borus JF: Functional somatic syndromes. Ann Intern Med 1999, 130:910-921.

29. Gureje O, Simon GE, Von Korff M: A cross-national study of the course of persistent pain in primary care. Pain 2001, 92:195-200.

30. Fan AZ, Strine TW, Jiles R, Mokdad AH: Depression and anxiety associated with cardiovascular disease among persons aged 45 years and older in 38 states of the United States, 2006. Prev Med 2008, 46:445-450.

31. Yanovski SZ, Nelson JE, Dubbert BK, Spitzer RL: Association of binge eating disorder and psychiatric comorbidity in obese subjects. Am J Psychiatry 1993, 150:1472-1479.

32. Carroll D, Phillips AC, Thomas GN, Gale CR, Deary I, Batty GD: Generalized anxiety disorder is associated with metabolic syndrome in the Vietnam experience study. Biol Psychiatry 2009, 66:91-93.

33. Lydiard RB: Irritable bowel syndrome, anxiety, and depression: what are the links? J Clin Psychiatry 2001, 62:38-45. discussion 46-37.

34. Harter MC, Conway KP, Merikangas KR: Associations between anxiety disorders and physical illness. Eur Arch Psychiatry Clin Neurosci 2003, 253:313-320.

35. Simon NM, Blacker D, Korbly NB, Sharma SG, Worthington JJ, Otto MW Pollack MH: Hypothyroidism and hyperthyroidism in anxiety disorders revisited: new data and literature review. J Affect Disord 2002, 69:209-217.

36. Katon W, Lin EH, Kroenke K: The association of depression and anxiety with medical symptom burden in patients with chronic medical illness. Gen Hosp Psychiatry 2007, 29:147-155.

37. Cimpean D, Drake RE: Treating co-morbid chronic medical conditions and anxiety/depression. Epidemiol Psychiatr Sci 2011, 20:141-150.

38. DiMatteo MR, Lepper HS, Croghan TW: Depression is a risk factor for noncompliance with medical treatment: meta-analysis of the effects of anxiety and depression on patient adherence. Arch Intern Med 2000, 160:2101-2107.

39. Strik JJ, Denollet J, Lousberg R, Honig A: Comparing symptoms of depression and anxiety as predictors of cardiac events and increased health care consumption after myocardial infarction. J Am Coll Cardiol 2003, 42:1801-1807.

40. Unutzer J, Schoenbaum M, Katon WJ, Fan MY, Pincus HA, Hogan D, Taylor J: Healthcare costs associated with depression in medically ill fee-for-service medicare participants. J Am Geriatr Soc 2009, 57:506-510.

41. Cohen S, Rodriquez MS: Pathways linking affective disturbances and physical disorders. Health Psychol 1995, 14:374-380. 
42. Kiecolt-Glaser JK, McGuire L, Robles TF, Glaser R: Emotions, morbidity, and mortality: new perspectives from psychoneuroimmunology. Annu Rev Psychol 2002, 53:83-107.

43. Irwin M, Patterson T, Smith TL, Caldwell C, Brown SA, Gillin JC, Grant I: Reduction of immune function in life stress and depression. Biol Psychiatry 1990, 27:22-30.

44. Roy-Byrne PP, Davidson KW, Kessler RC, Asmundson GJ, Goodwin RD, Kubzansky L, Lydiard RB, Massie MJ, Katon W, Laden SK, Stein MB: Anxiety disorders and comorbid medical illness. Gen Hosp Psychiatry 2008, 30:208-225.

45. Friedman B, Lyness JM, Delavan RL, Chunyu L, Barker WH: Major depression and disability in older primary care patients with heart failure. J Geriatr Psychiatry Neurol 2008, 21:111-122.

46. Berk M, Jacobson BF, Hurly E: Fluoxetine and hemostatic function: a pilot study. J Clin Psychiatry 1995, 56:14-16.

47. Williams $\sqcup$, Henry MJ, Berk M, Dodd S, Jacka FN, Kotowicz MA, Nicholson GC, Pasco JA: Selective serotonin reuptake inhibitor use and bone mineral density in women with a history of depression. Int Clin Psychopharmacol 2008, 23:84-87.

48. Almeida OP, Alfonso H, Hankey GJ, Flicker L: Depression, antidepressant use and mortality in later life: the Health In Men Study. PLoS One 2010, 5:e11266.

49. Katon WJ: Epidemiology and treatment of depression in patients with chronic medical illness. Dialogues Clin Neurosci 2011, 13:7-23.

50. Brenes GA: Anxiety and chronic obstructive pulmonary disease: prevalence, impact, and treatment. Psychosom Med 2003, 65:963-970.

51. Pasco JA, Nicholson GC, Kotowicz MA: Cohort profile: Geelong Osteoporosis Study. Int J Epidemio/ 2012, 41:1565-1575.

52. First M, Spitzer R, Gibbon M, Williams J: Structured Clinical Interview for DSMINTR Axis I Disorders, Research Version, Non-patient Edition (SCID-I/NP). New York: Biometrics Research, New York State Psychiatric Institute; 2002.

53. Henry MJ, Pasco JA, Korn S, Gibson JE, Kotowicz MA, Nicholson GC: Bone mineral density reference ranges for Australian men: Geelong Osteoporosis Study. Osteoporos Int 2010, 21:909-917.

54. World Health Organisation: Obesity: preventing and managing the global epidemic. Report of a WHO Consultation. In WHO Technical Report Series 894. Geneva: WHO; 2000.

55. Giles C, Ireland P: Dietary Questionnaire for Epidemiological Studies (Version 2). Melbourne: The Cancer Council Victoria; 1996.

56. Australian Bureau of Statistics: Socio-Economic indices for Areas (SEIFA) Technical Paper. Canberra ABS: Australian Bureau of Statistics; 2006

57. Williams L, Jacka F, Pasco J, Henry M, Dodd S, Nicholson G, Kotowicz M, Berk M: The prevalence of mood and anxiety disorders in Australian women. Australas Psychiatry 2010, 18:250-255.

58. Brennan SL, Henry MJ, Wluka AE, Nicholson GC, Kotowicz MA, Pasco JA: Socioeconomic status and bone mineral density in a population-based sample of men. Bone 2010, 46:993-999.

59. Brennan SL, Henry MJ, Nicholson GC, Kotowicz MA, Pasco JA: Socioeconomic status, obesity and lifestyle in men: the Geelong Osteoporosis Study. J Men's Health 2010, 7:31-41.

60. Haug TT, Mykletun A, Dahl AA: Are anxiety and depression related to gastrointestinal symptoms in the general population? Scand J Gastroenterol 2002, 37:294-298.

61. Hu WH, Wong WM, Lam CL, Lam KF, Hui WM, Lai KC, Xia HX, Lam SK, Wong BC: Anxiety but not depression determines health care-seeking behaviour in Chinese patients with dyspepsia and irritable bowel syndrome: a population-based study. Aliment Pharmacol Ther 2002, 16:2081-2088.

62. Jansson C, Nordenstedt $H$, Wallander MA, Johansson S, Johnsen R, Hveem K, Lagergren J: Severe gastro-oesophageal reflux symptoms in relation to anxiety, depression and coping in a population-based study. Aliment Pharmacol Ther 2007, 26:683-691.

63. Avidan B, Sonnenberg A, Giblovich H, Sontag SJ: Reflux symptoms are associated with psychiatric disease. Aliment Pharmacol Ther 2001, 15:1907-1912.

64. Stovner L, Hagen $K$, Jensen R, Katsarava Z, Lipton R, Scher A, Steiner T, Zwart JA: The global burden of headache: a documentation of headache prevalence and disability worldwide. Cephalalgia 2007, 27:193-210.

65. Williams $L J$, Pasco JA, Jacka FN, Dodd S, Berk M: Pain and the relationship with mood and anxiety disorders and psychological symptoms. J Psychosom Res 2012, 72:452-456.
66. Lipton RB, Hamelsky SW, Kolodner KB, Steiner TJ, Stewart WF: Migraine, quality of life, and depression: a population-based case-control study. Neurology 2000, 55:629-635.

67. Morgan H, Blashki G: Fits, faints and funny turns. Could it be a mental disorder? Aust Fam Physician 2003, 32:211-213. 216-219.

68. Hoppe C, Elger CE: Depression in epilepsy: a critical review from a clinical perspective. Nat Rev Neurol 2011, 7:462-472.

69. Wilhelm K, Mitchell P, Slade T, Brownhill S, Andrews G: Prevalence and correlates of DSM-IV major depression in an Australian national survey. J Affect Disord 2003, 75:155-162.

70. De S: Prevalence of depression in stable chronic obstructive pulmonary disease. Indian J Chest Dis Allied Sci 2011, 53:35-39.

71. Williams LJ, Pasco JA, Jacka FN, Henry MJ, Dodd S, Berk M: Depression and bone metabolism. A review. Psychother Psychosom 2009, 78:16-25.

72. Mykletun A, Jacka F, Williams L, Pasco J, Henry M, Nicholson GC, Kotowicz MA Berk M: Prevalence of mood and anxiety disorder in self reported irritable bowel syndrome (IBS). An epidemiological population based study of women. BMC Gastroenterol 2010, 10:88.

73. Smith DF, Gerdes LU: Meta-analysis on anxiety and depression in adult celiac disease. Acta Psychiatr Scand 2012, 125:189-193.

74. Lopez-Colombo A, Morgan D, Bravo-Gonzalez D, Montiel-Jarquin A, Mendez-Martinez S, Schmulson M: The epidemiology of functional gastrointestinal disorders in Mexico: a population-based study. Gastroenterol Res Pract 2012, 2012:606174.

75. Irvine EJ: Quality of life assessment in gastro-oesophageal reflux disease. Gut 2004, 53:iv35-iv39.

76. Kroenke K, Price RK: Symptoms in the community. Prevalence, classification, and psychiatric comorbidity. Arch Intern Med 1993, 153:2474-2480.

77. losifescu DV, Nierenberg AA, Alpert JE, Smith M, Bitran S, Dording C, Fava M: The impact of medical comorbidity on acute treatment in major depressive disorder. Am J Psychiatry 2003, 160:2122-2127.

78. Kriegsman DM, Penninx BW, van Eijk JT, Boeke AJ, Deeg DJ: Self-reports and general practitioner information on the presence of chronic diseases in community dwelling elderly. A study on the accuracy of patients' self-reports and on determinants of inaccuracy. $J$ Clin Epidemio 1996, 49:1407-1417.

doi:10.1186/1741-7015-11-110

Cite this article as: Sanna et al:: Physical comorbidities in men with mood and anxiety disorders: a population-based study. BMC Medicine 2013 11:110

\section{Submit your next manuscript to BioMed Central and take full advantage of:}

- Convenient online submission

- Thorough peer review

- No space constraints or color figure charges

- Immediate publication on acceptance

- Inclusion in PubMed, CAS, Scopus and Google Scholar

- Research which is freely available for redistribution 